\title{
Determination of postmortem interval by decomposition changes: An ambiguous phenomenon
}

\author{
Abhishek Yadav*, Arijit Dey, Ramesh P Anuragi and Hemant Kanwar \\ Department of Forensic Medicine and Toxicology, All India Institute of Medical Sciences (AIIMS), Ansari Nagar, New Delhi, India
}

\begin{abstract}
Estimation of Postmortem Interval (PI) or Time since Death (TSD) is an important objective of post-mortem examination which connects an accused to that particular moment of time to prove his guilt or innocence and plays a vital issue in investigation of medico legal cases. In India, the PI/TSD is invariably mentioned in every post-mortem report done by the Forensic Pathologist and is mostly given on the basis of naked eye changes after death. Its estimation continues to be a challenge for the Forensic pathologists due to different variable factors. The authors present a case of a person who died in known time duration but his external putrefactive changes were far advanced as compared to the post-mortem changes expected at that PI as per the standard literature. The authors recommend intensive studies to be initiated in Indian settings to determine a scientific data for the actual time taken for the process of decomposition.
\end{abstract}

\section{Introduction}

Estimation of Post-mortem Interval (PI) or Time since Death (TSD) is an important objective of post-mortem examination which connects an accused to that particular moment of time to prove his guilt or innocence and plays a vital issue in investigation of medico legal cases. Its estimation continues to be a major problem for the Forensic pathologist particularly in tropical countries. In India, the gross external changes in a dead body after death are generally considered to opine about the time passed since death. The various gross changes in the body after death used for giving opinion about PI are loss of corneal reflex and changes in eye, cooling of the body, post mortem hypostasis, rigor mortis, decomposition and other putrefactive changes [1-8]. The Standard Text books of Forensic Medicine mentions a range of time duration in which each of these changes appear in a dead body [1-8]. The authors present a case of a person who died in known time duration but his external putrefactive changes were far advanced as compared to the post-mortem changes expected at that PI as per the standard literature.

\section{Case history}

The deceased was a middle aged male, with an alleged history of being a chronic alcoholic, a patient of hypertension and was under medication for several years. He was found in unresponsive condition in a vacant area near his house at about $12.28 \mathrm{pm}$. A lady living in the neighbourhood saw him walking in that place at about 06:30 am. The police was informed and he was brought to AIIMS hospital and declared as brought dead at $8.36 \mathrm{pm}$. Dead body was received in mortuary at $9.50 \mathrm{pm}$ on the same day and post mortem was conducted at $2 \mathrm{pm}$ on the next day. The body was preserved in cold chamber overnight till the start of autopsy.

\section{Autopsy findings}

The deceased was a forty two years old male of moderate nutrition and average built. Post mortem lividity was present over back and dependent part of body except over pressure areas. The following significant external findings were observed (Figures 1 and 2):
1. Rigor mortis had passed off,

2. There was greenish discoloration of abdomen, with peeling of skin of body,

3. Marbling present over shoulders,

4. Bloating of abdomen,

5. There was purging of blood from nostrils and mouth.

No external ante-mortem injury could be seen over the body. All the internal organs including brain, lungs, heart, liver, spleen and kidneys were soft, flabby and congested. Small intestine, large intestine, mesentery and pancreas showed decomposition changes. The heart was soft and flabby, weighing $309 \mathrm{gm}$. On dissection, the left anterior descending coronary artery showed atherosclerotic changes and was about $70 \%$ to $80 \%$ blocked in upper and middle portion respectively. The right coronary, left coronary artery and left circumflex arteries showed atherosclerotic changes and was about $30-40 \%$ blocked. The right coronary artery showed atherosclerotic changes and was about $30 \%$ blocked. Stomach contained about $100 \mathrm{ml}$ of partially digested food material. Mucosa was congested and the contents had an alcoholic smell. The right kidney was atrophic and left kidney had indistinct cortico-medullary junction.

\section{Discussion}

In the present case, if we look at the timeline of the incident, the deceased was seen alive at about 06:30 am in the morning and the body was finally shifted to the Mortuary cold chamber at 09:50 pm,

Correspondence to: Abhishek Yadav, Department of Forensic Medicine and Toxicology, All India Institute of Medical Sciences (AIIMS), Ansari Nagar, New Delhi, India, Tel: 09818052523; E-mail: drayad_in@yahoo.com

Key words: postmortem interval, time since death, decomposition changes, taphonomy, rigor mortis

Received: June 03, 2017; Accepted: June 24, 2017; Published: June 27, 2017 


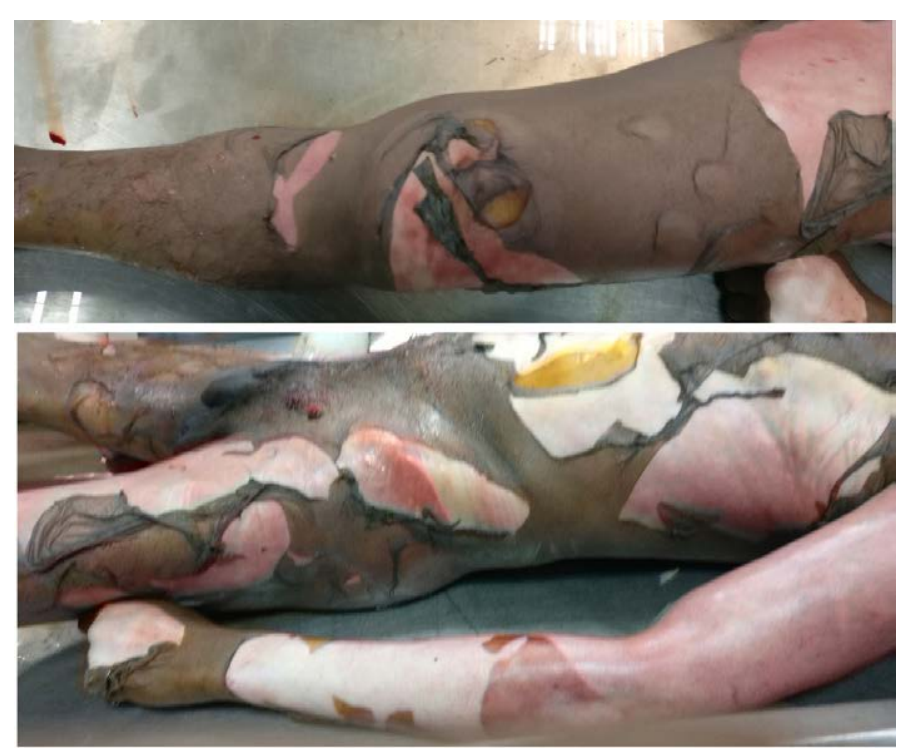

Figure 1. Decomposition changes- peeling of skin and bloating of abdomen.
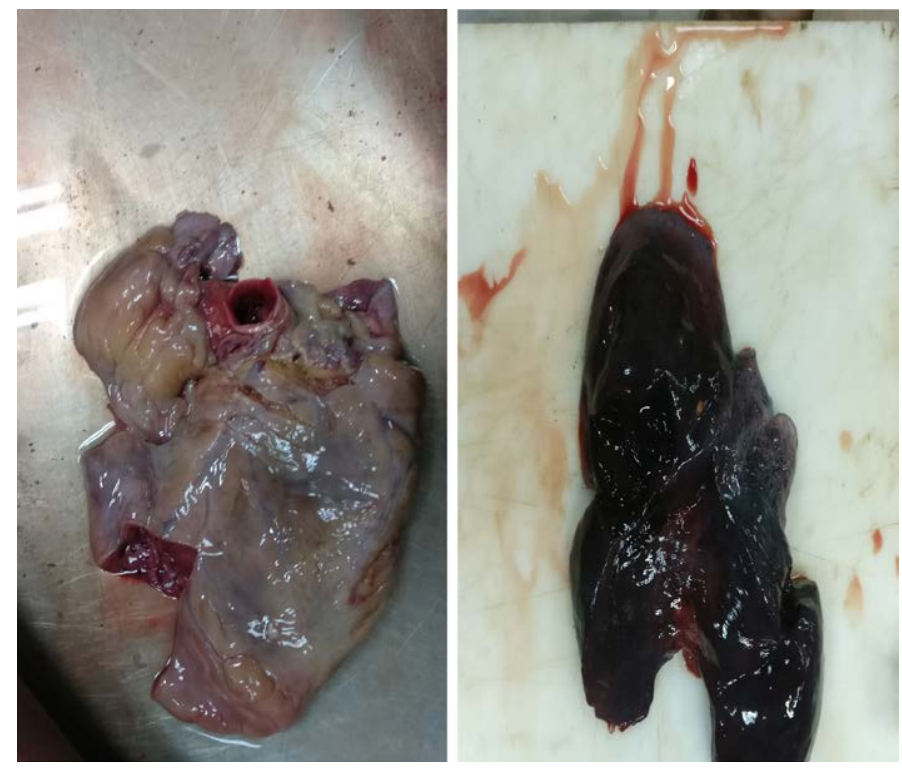

Figure 2. Soft and flabby heart and lung.

amounting to maximum 15 hours till he was last seen alive. The maximum time since death at the time of starting the autopsy was about 32 hours which included 17 hours when the body was preserved in the cold chambers at $4^{\circ} \mathrm{C}$ to stop the decomposition changes. But significant decomposition changes were observed during autopsy (Figures 1 and 2). Knight mentions that decomposition begins at a variable time after death and is expected to begin in an average temperate climate at about 3 days in unrefrigerated corpse [1]. Rigor mortis starts disappearing at the onset of decomposition [2]. The same was evident in the present case. The earliest sign of decomposition is greenish discoloration of the lower quadrants of the abdomen, visible in the first 24-36 hrs [2]. It may appear in 12-18 hours in summer and in 1-2 days in winter [4]. The marbling of skin begins in 24 hours and is visible in $36-48$ hours [4]. Slippage of skin is seen in about 60-72 hrs [2].

The deceased in the present case died within maximum range of 15 hours before the body was refrigerated but the decomposition was found which was expected to start in three days. So in this case, it is clearly evident that the decomposition findings were not corroborating with the standard Medical Literature. The Environment Temperature and Moisture, particularly in Tropical Countries, influence the onset of putrefaction [1-8]. The incident took place on $20^{\text {th }}$ February 2017 which is a pleasant month in Delhi and temperature on the day was $32^{\circ} \mathrm{C}$ maximum and $21^{\circ} \mathrm{C}$ minimum, which cannot be considered too much on the higher side. Decomposition is hastened by obesity, heavy clothing, and sepsis, all of which keep the body warm [2]. None of these conditions were present in the case. Though the body was preserved in cold chambers but the literature says that the refrigeration of the body may not necessarily stop decomposition completely $[2,4]$. So it can be inferred that the body was already in a state of the decomposition when it was kept in cold chambers.

The authors while searching the literature for this case report came across an important aspect that no studies has been done in India in recent times regarding estimation of PI/TSD from naked eye changes like rigor mortis and decomposition in the body after death. Few studies have been done in the past in other countries [9-14]. In India, the PI/TSD is invariably mentioned in every postmortem report done by the Forensic Pathologist and is given on the basis of naked eye changes after death. This is a matter of grave concern because the authors from their experience as Forensic Pathologist in India have attended numerous Judicial Proceedings in criminal cases and have observed that the Honorable Judges rely heavily on the Time since death given in the autopsy report to decide the culpability of an accused. Both Knight [1] and Dimaio [2] have commented that all the methods used to determine PI/TSD are unreliable and inaccurate. The circumstantial evidences are more accurate than the scientific methods as seen in our case also where a witness saw the deceased alive at the time which would have been contrary if the PI is calculated depending upon the decomposition changes. Thus a wrong interpretation can lead to a gross miscarriage of justice with an accused going scot free or an innocent man being harassed for criminality.

\section{Conclusion}

The Investigating Agencies and the Judiciary should be made aware of the fallacy that the exact time of death cannot be fixed by any method, but only an approximate range of death can be given, that too will have considerable biological variations in individual cases. Detailed Taphonomical studies should be initiated in Indian settings regarding this aspect like "Body Farms" so as to obtain a scientific data for the actual time taken for the process of decomposition to start and get completed in tropical climate with seasonal variations.

\section{References}

1. Saukko P, Knight B (2016) Forensic pathology. The Pathophysiology of death (4thedn). Boca raton: CRC Press, Pp. 55-93.

2. DiMaio VJ, Dimaio D (2001) Forensic Pathology. Time of Death. ( $2^{\text {nd }}$ edn). Boca Raton: CRC Press Pp. 21-41.

3. Matiharan K, Patnaik AK (2005) Modi's Medical Jurisprudence and Toxicology. Postmortem Changes and Time Since Death. (23 ${ }^{\text {rd }}$ edn). LexisNexis New Delhi, India Pp. 423-461.

4. Reddy KSN (2014) The essentials of forensic medicine and toxicology. Postmortem changes. (33rdedn). Jaypee Brothers, New Delhi, India, Pp. 152-178.

5. Mahanta P (2014) Modern Textbook of Forensic medicine \& Toxicology. Thanatology Jaypee Brothers, New Delhi, India, Pp. 184-195.

6. Aggarwal A (2014) Textbook of Forensic Medicine and Toxicology. Signs of death and changes following death. Avichal Publishing Company, New Delhi, India Pp. 173-199.

7. Vij K (2014) Textbook of Forensic Medicine and Toxicology: Principles and practice. Sudden and Unexpected death. ( $6^{\text {th }}$ edn). Elsevier India Pvt Ltd, New Delhi, India, Pp. 97-105. 
8. Rao NG (2010) Textbook of Forensic Medicine \& Toxicology. Thanatology. Jaypee Brothers, New Delhi, India, Pp. 143-161.

9. http://www.accuweather.com/en/in/delhi/202396/february-weather/202396

10. Galloway A, Birkby WH, Jones AM, Henry TE, Parks BO (1989) Decay rates of human remains in an arid environment. J Forensic Sci 34: 607-616. [Crossref]

11. http://digitalscholarship.unlv.edu/thesesdissertations/1139
12. Cockle DL, Bell LS (2017) The environmental variables that impact human decomposition in terrestrially exposed contexts within Canada. Sci Justice 57: 107117. [Crossref]

13. Maile AE, Inoue CG, Barksdale LE, Carter DO (2017) Toward a universal equation to estimate postmortem interval. Forensic Sci Int 272: 150-153. [Crossref]

14. Roberts LG, Spencer JR, Dabbs GR (2017) The Effect of Body Mass on Outdoor Adult Human Decomposition. J Forensic Sci [Epub ahead of print]. [Crossref]

Copyright: @2017 Yadav A. This is an open-access article distributed under the terms of the Creative Commons Attribution License, which permits unrestricted use, distribution, and reproduction in any medium, provided the original author and source are credited. 